\title{
PERCEPÇÃO DE FAMILIARES SOBRE O CUIDADO À PESSOA COM CÂNCER EM ESTÁGIO AVANÇADO ${ }^{1}$
}

\author{
Edite Lago da Silva Sena², Patrícia Anjos Lima de Carvalho³, Helca Franciolli Teixeira Reis ${ }^{4}$, Maricélia Braga \\ Roch $a^{5}$
}

\begin{abstract}
${ }^{1}$ Recorte da pesquisa - Vivências de familiares cuidadores de pessoas com câncer em estágio avançado, do Curso de Enfermagem, Departamento de Saúde (DS) da Universidade Estadual do Sudoeste da Bahia (UESB), 2008.

${ }^{2}$ Doutora em Enfermagem. Docente do Programa de Pós-Graduação em Enfermagem e Saúde (PPGES) da UESB. Bahia, Brasil. E-mail: editelago@gmail.com

${ }^{3}$ Mestre em Enfermagem e saúde pelo PPGES/UESB. Professora Auxiliar do DS/UESB. Bahia, Brasil. E-mail: patricia.anjos3@ gmail.com

${ }^{4}$ Mestre em Enfermagem e saúde pelo PPGES/UESB. Professora Assistente da Universidade Federal da Bahia, campus de Vitória da Conquista-BA. Bahia, Brasil. E-mail: helcareis@gmail.com

${ }^{5}$ Enfermeira do Hospital Esaú Matos em Vitória da Conquista-BA. Bahia, Brasil. E-mail: mariceliabraga@hotmail.com
\end{abstract}

\begin{abstract}
RESUMO: Com o objetivo de compreender a intencionalidade operante na experiência de cuidado à pessoa com câncer em estágio avançado, na percepção do familiar cuidador, foi realizada uma investigação, por meio de entrevistas não diretivas, com cinco familiares cuidadores de pessoas com diagnóstico de câncer em estágio avançado, atendidas no Ambulatório de Oncologia de um hospital público do interior da Bahia, no primeiro semestre de 2008. Como se tratava de estudo fenomenológico, as descrições vivenciais foram submetidas à analítica da ambiguidade, possibilitando a percepção do eixo temático denominado "cuidando e sendo cuidado - uma experiência de entrelaçamento". Desvelado o fenômeno, foi possível compreender que, na relação do cuidar, as pessoas envolvidas vivem uma experiência ambígua que abre possibilidades à transcendência, envolvendo transformação de visões de mundo, atitudes e percepções. Nesse sentido, as ações em saúde devem estar voltadas à relação dialógica e à intersubjetividade, inerentes ao contexto do cuidar, no qual devem se inserir também os cuidadores.
\end{abstract}

DESCRITORES: Cuidado. Família. Filosofia em enfermagem.

\section{FAMILY MEMBERS' PERCEPTIONS ON CARE GIVEN TO PEOPLE WITH ADVANCED CANCER STAGE}

\begin{abstract}
This is a phenomenological study that aimed to understand the operative intentionality on the care experience for people with advanced cancer from the perspective of family caregivers. The research was conducted through non-directive interviews with five family caregivers of people diagnosed with advanced cancer attended at the Oncology Outpatient Clinic in a public hospital in inland Bahia, Brazil, in the first semester of 2008. As a phenomenological study, the experiential descriptions were submitted to ambiguity analysis, resulting in perceiving the main theme "giving care and being cared for: an interlacing experience". With the phenomenon unveiled, it was possible to understand that within the care relationship, the people involved live an ambiguous experience that opens up possibilities for transcendence, involving a transformation of world views, attitudes, and perceptions. In this way, health actions must be focused on dialogical relationships and on inter-subjectivity, both inherent to care context, in which the caregivers should be also included.
\end{abstract}

DESCRIPTORS: Care. Family. Philosophy in nursing.

\section{PERCEPCIÓN DE LA FAMILIA SOBRE EL CUIDADO A LA PERSONA CON CÁNCER AVANZADO}

RESUMEN: Estudio fenomenológico con el objetivo de comprender la intencionalidad operante en la experiencia de cuidado a la persona con cáncer avanzado desde la perspectiva del cuidador familiar. La investigación se realizó a través de entrevistas no directivas con cinco cuidadores familiares de personas diagnosticadas con cáncer avanzado, atendidas en el Ambulatorio de Oncología de un hospital público en el interior de Bahía, en el primer semestre de 2008. Las descripciones de la experiencia vivida se examinaron según la analítica de la ambigüedad, lo que permitió la percepción del tema principal: "cuidar y ser cuidado - una experiencia de entrelazamiento". Al revelar el fenómeno se pudo comprender que en la relación del cuidado, las personas involucradas viven una experiencia ambigua que abre posibilidades a la trascendencia, la transformación de la visión de mundo, las actitudes y percepciones. De esta manera, las acciones de salud deben centrarse en la relación dialógica y en la intersubjetividad, inherentes al contexto del cuidar, en el cual también se debe incluir los cuidadores.

DESCRIPTORES: Cuidado. Familia. Filosofía en enfermería. 


\section{INTRODUÇÃO}

Com o aumento da expectativa de vida da população brasileira, observa-se a elevação dos índices de doenças cronicodegenerativas e, dentre estas, as neoplasias, que vêm ganhando importância no perfil de morbimortalidade do país, ocupando o segundo lugar como causa de óbito e configurando-se como um problema de saúde pública. Desde 2003, dados estatísticos brasileiros já mostravam que o câncer constitui importante causa de doença e morte no Brasil, visto que as neoplasias malignas são consideradas a segunda causa de morte na população e representam quase $17 \%$ dos óbitos de causa conhecida, notificados em 2007 no Sistema de Informações sobre Mortalidade. ${ }^{1}$

A debilidade causada pelo câncer implica em uma condição de dependência que, por sua vez, necessita de maiores cuidados, seja de um familiar ou de outro cuidador, formal ou voluntário, enfim, alguém que possa intervir junto à pessoa. No Brasil, há uma tradição segundo a qual o cuidado de um familiar doente é de responsabilidade da família, sobretudo quando a pessoa que necessita de cuidado for pai, mãe, filhos, devendo estes últimos amparar e ajudar os pais em situações de velhice, carência ou enfermidade. ${ }^{2}$ Há, portanto, uma naturalização do papel da família como cuidadora.

Mediante os encargos socioculturais assumidos pela família nesta função, ela se torna essencial após o diagnóstico de uma doença grave como o câncer, tanto pela valorização da função no processo saúde-doença de todos os seus membros, quanto pela elevação da incidência de doenças crônicas que estão adquirindo uma importância crescente nos problemas relativos ao sistema de saúde. ${ }^{3}$

A relação do câncer com a dor, o sofrimento, a deterioração do ser e a sensação de finitude remete à importância do cuidado - que não deve ser limitado à doença e a suas manifestações físicas. Portanto, a família deve estar preparada para compreender e oferecer apoio emocional ao ser com câncer frente aos conflitos e dificuldades, enfim, às necessidades de cuidado.

O cuidado pode ser expresso através de comportamentos e ações que envolvem conhecimento, valores, habilidades e atitudes empreendidas no sentido de favorecer as potencialidades das pessoas para manter ou melhorar as condições humanas no processo de viver e morrer. ${ }^{4}$

Na perspectiva heideggeriana, o cuidado representa um fenômeno ontológico existencial bási$\mathrm{co}$, que se pode traduzir como a base que possibilita a existência humana como tal e, assim, o cuidar é percebido como algo inerente ao homem ou um modo-de-ser essencial que excede a concepção de um momento de atenção, zelo e desvelo: representa uma atitude de dimensões muito maiores, incluindo ocupação, preocupação, responsabilização e envolvimento afetivo com o outro. ${ }^{5-6}$

Em nossa experiência de enfermeiras junto a familiares que são designados ou se autodesignam para a função de cuidador de uma pessoa com câncer, temos observado várias alterações e conflitos, uma vez que, ao perceberem que essa posição requer conhecimentos e habilidades específicas acerca da doença, expressam sentimento de medo, desespero, diminuição da motivação para a vida e até uma ansiedade existencial ou outros aspectos comprometedores de sua saúde global.

Essas reflexões geraram vários questionamentos até que foi possível estabelecer a seguinte pergunta norteadora do estudo: o que motiva o familiar de uma pessoa com câncer em estágio avançado a ocupar-se com o cuidado? A partir desta pergunta, foi estabelecido o objetivo do estudo: compreender a intencionalidade operante na experiência do processo de cuidar de pessoas com câncer em estágio avançado, na percepção do familiar cuidador.

\section{CAMINHO METODOLÓGICO}

Por se tratar de um estudo vivencial, foi adotada uma abordagem qualitativa, de natureza fenomenológica. Nesta perspectiva, o referencial teórico-filosófico selecionado para fundamentar a análise foi a filosofia da experiência de Maurice Merleau-Ponty, que contempla o vivido, com vistas à descrição de fenômenos tais como sentimentos, valores, ideias e crenças que se mostraram a partir da intersubjetividade resultante da relação entre pesquisador e participantes do estudo. ${ }^{7-9}$ Esta concepção fenomenológica parte da noção de que nenhum discurso clássico consegue expressar de forma inequívoca o que é a percepção, já que a perspectiva traz consigo o anúncio de uma coisa que é mais do que aquilo que se apresenta, e que não depende da síntese de alguém. ${ }^{7}$

As vivências funcionam exatamente desta maneira: a cada momento visualizamos um perfil que traz consigo uma série de outros perfis, o que nos faz compreender que a maneira como vivenciamos a percepção é ambígua e tem a ver com o paradoxo entre o mundo que se revela para nós - o "em si" - e nossa tendência em direção ao mundo - o "para si". 
Assim sendo, envolve a consciência pré-reflexiva (sentimento) e a consciência reflexiva (pensamento, linguagem), em que se instala o universo de significações. A experiência ambígua mostra-se a partir de depoimentos, que revelam fenômenos, ou seja, o mundo aparece para nós parcialmente, porém, arrasta consigo um horizonte de passado que retomamos em nossa vivência perceptiva. ${ }^{7}$

Deste modo, percebemos nossas vivências como uma experiência intersubjetiva e intercorporal, própria da relação pessoa-pessoa, em que ambas vivem, ao mesmo tempo, duas naturezas: uma, que é pré-pessoal ou pré-reflexiva e refere-se aos sentimentos, e outra, que é pessoal ou reflexiva e relaciona-se com a racionalidade humana. Esta compreensão baseia-se na noção de intercorporeidade de Merleau-Ponty, que afirma ser a nossa relação corporal com o mundo uma generalidade, pois uma ínfima distância se instala entre um " $\mathrm{eu}^{\prime}$ e um "outro", ou seja, na relação, somos como dois círculos quase concêntricos, manifestando-se apenas com uma leve e misteriosa diferença. ${ }^{9-10}$

O estudo foi realizado no Ambulatório de Oncologia e na Clínica Médica de um hospital público do interior da Bahia. Entrevistamos cinco familiares cuidadores de pessoas com câncer em estágio avançado, no período de abril a julho de 2008. O número de participantes foi estabelecido no decorrer das entrevistas, quando, por meio de leitura das descrições vivenciais obtidas, percebemos o desvelar do fenômeno, de forma ambígua, como uma generalidade pertencente a todos os seres humanos. ${ }^{7}$ Portanto, as entrevistas foram cessadas porque as descrições revelaram-se suficientes para responder à questão da pesquisa e, portanto, a alcançar o objetivo do estudo.

Os dados foram coletados por meio de entrevista não diretiva, gravada individualmente, sem delimitação de tempo, com os familiares que, voluntariamente, se dispuseram a participar do estudo, mediante encontros formais em data, horário e local de escolha deles. Tal procedimento ocorreu após a aprovação do projeto pelo Comitê de Ética em Pesquisa com Seres Humanos da Universidade Estadual do Sudoeste da Bahia, inscrito sob o protocolo $n^{\circ} 012 / 2008$, e a obtenção de assinaturas dos entrevistados no Termo de consentimento livre e esclarecido, respeitando os aspectos éticos pertinentes à pesquisa, conforme determina a resolução no 196/1996, do Conselho Nacional de Saúde. ${ }^{11}$ Para garantir o anonimato dos sujeitos utilizamos nomes fictícios, designando-os pelos nomes de pedras preciosas.
Obtidas as descrições vivenciais, procedemos a sua análise, com base na analítica da ambiguidade, técnica que consiste nos seguintes passos: organizar o texto a partir da transcrição das descrições vivenciais gravadas nas entrevistas com os sujeitos da pesquisa; realizar leituras exaustivas do material, partindo da compreensão de que se trata de um estudo fenomenológico e, como tal, busca descrever vivências, experiências perceptivas que acontecem em um campo fenomenal, e não explicá-las; fazer ver os fenômenos em si mesmos, a partir de si mesmos, o que significa dizer que o pesquisador vive sua experiência perceptiva durante a leitura e se reconhece como generalidade intercorporal. Com isto, corrobora-se a concepção de que o conhecimento constitui-se a partir da interação com o outro, efetivam-se objetivações, operações expressivas que transmutam do polo pré-reflexivo ao reflexivo através de processo realizado pela linguagem, estando os pesquisadores sempre certos de que as ambiguidades que se mostram são inúmeras. ${ }^{10,12-13}$

Investidos dessas noções, estamos em regime de redução eidética, ou seja, fazendo fenomenologia, a partir da suspensão das teses de que as coisas são em si mesmas, e fazendo ver essências (ambiguidades), que têm a ver com a percepção, com o reconhecimento de que o fenômeno sempre se mostra em perfil, porém arrasta consigo outros perfis.

\section{RESULTADOS E DISCUSSÃO}

A aplicação da analítica da ambiguidade apontou o eixo temático: cuidando e sendo cuidado - uma experiência de entrelaçamento. Neste eixo, a experiência de cuidado da pessoa com câncer em estágio avançado apareceu como algo que ocorre de forma intersubjetiva e intercorporal e que, por se tratar de uma vivência fenomênica, possui uma intencionalidade que fundamenta e mobiliza a relação interpessoal, constituindo um entrelaçamento em que não se sabe exatamente quando se está sendo cuidador ou quando se está sendo cuidado.

Nesse contexto, o cuidar constitui uma experiência ambígua, pois envolve atitudes irrefletidas e reflexivas, podendo ser visto como uma boa ambiguidade, no sentido em que permite a transcendência, ou seja, toda experiência constitui uma oportunidade de alguém tornar-se "um outro" no que refere ao desenvolvimento pessoal. ${ }^{12}$ Esta constitui uma compreensão ampliada da noção de cuidado, não o reduzindo à atividade ou tarefa realizada para tratar uma ferida, aliviar 
um desconforto ou auxiliar na cura de uma doença, por exemplo, mas como forma de viver, de relacionar-se.

$\mathrm{Na}$ perspectiva do pensamento merleau-pontyano, o cuidado ocorre à consciência como um fenômeno, mostra-se em nossa experiência e molda a nossa prática, não podendo ser considerado como objeto independente de nós e, conforme preconiza Boff, não temos cuidado, somos cuidados. ${ }^{6}$

Assim, o cuidado despertado pelo desejo natural de ajudar não pode ser visto apenas como uma atitude altruísta em que não há intenção de obter benefícios ou resultados por parte de quem cuida, apesar de a descrição a seguir, em si, não revelar a intencionalidade operante, um dar-se conta de outras perspectivas ou perfis:

[...] o principal cuidado para mim era o amor. A gente procurava dar bastante amor, [...]. Cuidar é procurar fazer tudo, de uma maneira que a pessoa que está doente não sinta que ela está sendo um estorvo na sua vida, passar bastante amor, sentimento que cura, não cura a doença, mas fortalece a alma (Ametista).

Nesta fala, o cuidado é desvelado como um objeto, algo em si mesmo, que pertence à pessoa que cuida (cuidador) e que é ofertado a alguém, exprimindo uma noção objetivista de cuidado. Do mesmo modo, tal atitude nos remete à noção subjetivista de cuidado, em que o familiar atua a partir de uma subjetividade interior, de um sentimento abnegado, movido pela razão de que a pessoa cuidada não pode sentir-se constrangida em receber o cuidado que lhe é oferecido. No entanto, o cuidado constitui um fenômeno, e, portanto, não tem um locus, não pertence a uma pessoa, mas "ocorre", se "desvela", "aparece", surge quando duas pessoas ou mais interagem. ${ }^{10,12-13}$

Desvelando-se como experiência intersubjetiva, o cuidado caracteriza-se como uma vivência ambígua, isto é, mostra-se sempre em perfil, a cada momento do cuidar nos ocorre uma nova percepção, um novo modo de ser, um novo modo de cuidar e, assim, o cuidado vai sendo criado e recriado. ${ }^{7}$

Todos os sentimentos ambíguos que se exprimem em nossas vivências de cuidado são movidos por uma intencionalidade que, em muitos momentos, encontra-se velada, permanece invisível: o cuidador não consegue perceber que a atitude de cuidar do outro, do familiar com câncer em estágio avançado, é sempre um cuidado de si. Assim, quando cuidamos de alguém estamos cuidando de nós mesmos. ${ }^{10,12-13}$
Sob a perspectiva heideggeriana, ao ocupar-nos do cuidado de alguém, nosso ser de cuidador fica encoberto na pessoa de quem cuidamos, ou seja, quando investimos intensamente no cuidado de outrem, este vela o nosso ser como cuidador. ${ }^{14}$ Esta experiência se mostrou nas descrições vivenciais dos informantes do estudo. Ao serem capturados pela vivência do cuidado, eles passam a vê-lo como uma atitude de total doação ao ente querido e não percebem que cuidando do outro estão cuidando de si.

Quando Quartzo disse: [...] a gente [...] passa a viver só aquele momento ali [...] e Ametista comentou: [...] eu procurava forças para ajudar mesmo, não pensava em mim, em momento algum, era só ela, ela, ela. Vivia para ela [...], demonstraram não compreender o vínculo intersubjetivo que estabelece com seu familiar e que a intencionalidade que os orienta no processo de cuidar implica no cuidado de si mesmos. Neste caso, o cuidado é percebido como algo que ofusca a existência do Ser cuidador, de tal modo que, ao ocupar-se do outro, o seu ser fica encoberto, em um processo designado como cuidado inautêntico, ${ }^{14}$ pois passa a configurar-se como impessoalidade, a carne sensível, o invisível, o ser anônimo, o ser bruto, o ser selvagem..$^{8-10}$

Assim, entendemos que o envolvimento no cuidar tem a ver com o mundo da vida, ${ }^{15}$ que é a impessoalidade, os sentimentos que, em nossa história existencial, encontram-se em déficit e são preenchidos quando vivenciamos um vínculo gozoso na experiência do cuidado de outrem. Além disso, a escolha de tornar-se cuidador relaciona-se com o mundo da cultura, ${ }^{15}$ que significa o nosso dever moral, nossa imagem pessoal e social e, assim, com os princípios morais que constituímos por meio da educação, como se desvela na descrição:

[...] acho que a família tem que ter muito amor, se não tiver muito amor não cuida não. [...] eu iria pagar uma pessoa para cuidar, mas eu tinha prazer em fazer, porque o que ela mais queria é que cuidasse dela, como eu cuidei do meu pai [...] então, acho que devido a ela ser uma boa mãe, todo mundo na hora, ninguém recusou fazer nada por ela (Madrepérola).

A descrição acima corrobora a noção de cuidado inautêntico e demonstra que o envolvimento intenso com o Ser cuidado pode estar relacionado com o cuidado anônimo do cuidador. Não obstante, numa perspectiva objetivista, ocorre-nos a tentativa de explicar o evento, criando motivos socioculturais, como defendendo a tese de que a filha cuida de sua mãe movida por princípios morais, pois, em nossa sociedade, cuidar dos pais em situação 
de doença constitui um dever moral e propicia a valorização de sua pessoalidade. Logo, podemos compreender o cuidado do outro como um cuidado de si, cuidado este que muitas vezes encontra-se invisível, velado: o cuidador realiza o cuidado de si de modo inconsciente, configurando a ambiguidade que é característica do viver humano.

Nesta perspectiva, quando nos ocupamos do cuidado de outrem, de alguma forma cuidamos da preservação de nossa imagem social, de nossa reputação. Trata-se, portanto, de um cuidado de si, pois, se não cuidamos de um ente querido, podemos ser difamados e, do ponto de vista psicológico, isso pode nos afetar, deixar-nos ansiosos. A pessoa que é educada para ser cortês, generosa, para valorizar seus pais, se assim não o fizer, poderá desenvolver um sentimento de culpa que envolve atividades destrutivas pelas quais a pessoa pune a si mesma, indicando uma atitude de autorrejeição, que se expressa por meio de pesadelos, fobias, obsessão, ou pela retomada de sentimentos dolorosos. ${ }^{16}$ Por exemplo, o sentimento de culpa desvelado pelos familiares foi evidenciado na seguinte descrição: [...] a gente lembra os momentos bons que a gente já teve, [...] lembra de algo que aquela pessoa não gostou. Aí, você se sente culpada pelas coisas que poderia ter feito e não fez. É complicado! (Quartzo).

Neste perfil, o cuidado aparece também como uma atitude de compensação e retribuição. Em diversas descrições, os cuidadores se referem ao cuidado como retribuição àquilo que seu familiar propiciou-lhe no passado, revelando um cuidado de si inautêntico. Contudo, demonstram não ter a compreensão de que essa atitude de retribuir constitui um cuidado de si, visto que o cuidado passa a ser percebido como uma troca de favores.

Na descrição a seguir, Ametista expressa um sentimento de dever cumprido, identificado pela gratidão ao estar cuidando, o que lhe produz uma sensação de conforto.

[...] ela ficou lá [em Salvador] comigo, em todos os momentos difíceis [...] acho que ela fez a parte dela, da melhor forma possível [...]. Então, no momento mais difícil, foi eu que estava com ela [...]. Ela morreu feliz, estava do meu lado, eu dava bastante amor para ela [...]. Aí, eu me sentia assim, aliviada, aliviada não, não é a palavra certa, era um conforto para mim [...] eu acredito muito em destino, ela veio pra aqui, pra me proteger, me ajudar a crescer como pessoa, como profissional e eu vim justamente para retribuir (Ametista).

Contudo, a cada momento o cuidado mostrou-se em perfil, confirmando que a vivência constitui uma experiência ambígua e que não podemos limitar nossa percepção à figura que se mostra à primeira vista, mas visualizar aquelas que se fazem ver a partir do fundo que compõe a paisagem. ${ }^{7}$ Observamos a ambiguidade existente no cuidado quando este aparece alternando-se como cuidado de si inautêntico e autêntico, como se pode perceber na descrição vivencial a seguir: [...] Deus me colocou no mundo com essa missão [...] porque Deus sabia que ela um dia iria adoecer, e precisar de alguém. [...] era uma mãe maravilhosa, uma pessoa maravilhosa, a única pessoa que eu tinha na minha vida assim, era minha mãe (Ágata).

$\mathrm{Na}$ fala acima, o cuidado de si aparece como um não saber de si, um anônimo que motiva o cuidar. Este aspecto caracteriza a inautenticidade do cuidado. Por outro lado, o cuidado de si manifesta-se como um saber de si, ou seja, um cuidado de si autêntico, orientado pela cultura religiosa fundamentada no cristianismo, em que o contexto do cuidado passa a ser compreendido e aceito como um desígnio divino. ${ }^{17}$ A partir da doutrina cristã, compreende-se que, ao realizar a vontade de Deus, a pessoa conseguirá alcançar a promessa de uma vida eterna em um mundo sem dor, sem sofrimento, sem lágrima, sem morte.

$\mathrm{Na}$ tentativa de clarificar a diferença entre cuidado inautêntico e autêntico, retomamos a concepção fenomenológica de cuidado e o entendimento da noção de generalidade merleau-pontyana. ${ }^{7}$ A partir dessas noções, compreendemos que o cuidado não é algo originado na racionalidade, nem é intrínseco ao cuidador, mas é algo que se desvela na intersubjetividade, a partir da interação com o outro, constituindo uma unidade que não é exclusivamente de uma pessoa, mas também do outro e do mundo.Sob este olhar, percebemos um entrelaçamento do ser cuidador com o ser cuidado.

A literatura tem apontado com ênfase que o câncer, em nossa cultura, está associado às experiências saturadas de sofrimento e dor, seguidas de morte. ${ }^{18-19}$ Nesse estudo, também encontramos alguns sentimentos compartilhados pelo Ser cuidado e pelo Ser cuidador: a dor, o sofrimento, a angústia, a insegurança e outros, fazendo-nos perceber a generalidade existente entre eu e o outro, como se pode notar nas falas:

[...] não teve tratamento de jeito nenhum [...]. Muito difícil, muita dor, muito sentimento. Porque eu sabia que a doença dele no momento não tem cura. [...] é uma coisa que me dói muito, eu sofro demais! Eu não queria que ele acabasse desse jeito. Eu não queria que ele acabasse desse jeito (Jaspe). 
[...] ela morreu contra a vontade dela; lutou até o último momento para não morrer; o tratamento foi horrível, horrível! [...] Chorei demais, porque o sofrimento é muito grande; ela foi se definhando cada dia que passava e o que mais me doía era que ela queria viver e a gente não poderia fazer mais nada (Madrepérola).

Ao vivenciar o sofrimento do Ser com câncer, o Ser cuidador passa a compartilhar da dor física do outro, e poderá passar, em alguns casos, a visualizar a sua própria morte. A este momento em que ele percebe a possibilidade de sua própria morte, Heidegger denominou de cuidado autêntico ou cuidado de $\mathrm{si}^{14}$, e este é um cuidado que, muitas vezes, produz angústia no cuidador, que sofre ao se deparar com o seu próprio ser. ${ }^{10}$ Porém, a angústia vivenciada pelo cuidador, por constituir uma experiência ambígua, pode ser originada tanto do sentimento de perda progressiva do outro, quanto da percepção da própria finitude, conforme se pode perceber na fala:

[...] um dia ela passou muito mal, e a gente a levou para o CICAN para tentar o internamento. O médico conversou com a gente [...] não falou que ela estava no estágio terminal, falou indiretamente [...]. Na hora que soube, passou um filme na minha cabeça, foi o primeiro caso assim na família, caso assim mais próximo de mim [...]. Eu sempre falei que não aguentaria perder uma pessoa da minha família (Ametista).

Neste relato, a cuidadora demonstra um cuidado de si autêntico, ao buscar ocupar-se com atividade externa ao contexto da vivência de cuidadora. Neste sentido, ao enfrentar a possibilidade de interrupção da experiência do outro do outro, ou seja, da morte da tia, ela deixaria de receber o carinho, a orientação, enfim, qualquer ganho que ela poderia ter ao conviver com sua tia.

O contexto que envolve o cuidado abre possibilidade para que o cuidador visualize a sua própria morte, tanto a morte física quanto a morte da experiência do outro, isto é, da transcendência ou crescimento socioantropológico, e é neste momento que o cuidado de si aparece, como se pode perceber na fala de uma cuidadora ao refletir sobre o falecimento de sua mãe: [...] tenho me sentido muito cansada, parece que o cansaço dos tempos que perdi não vai passar nunca. A gente tem uma sensação que vai voltar para aquele lugar e também vai adoecer (Ágata).

Deste modo, o entorno do cuidado constitui uma vivência de progressiva finitude, e isto gera enorme ansiedade no cuidador, que passa a configurar o contexto existencial como uma vivência de sobrecarga e, de fato, trata-se de uma sobrecarga, uma vez que, em sua trajetória socioantropológi- ca, ele vem acumulando uma série de "cargas". Mediante a necessidade de cuidado, o familiar depara-se com a situação de renúncia dos vínculos sociais que possuía, o que contribui significativamente para que comece a perceber o cuidado do outro como uma barreira ao desenvolvimento de projetos de vida, conforme se pode evidenciar nas falas que se seguem:

[...] é saturador para a gente, porque eu tinha minha casa, filho, esposa, tinha meu dia a dia, minha vida [...]. Era tão turbulento que eu ficava sufocado, sufocado entre a necessidade de estar com meu pai e a razão de ter que trabalhar (Quartzo).

[...] tem sido uma vida muito cansada, muito difícil mesmo. Tem que ter força de vontade e coragem, porque se esmorecer não faz nada [...]. Amanhã vai fazer oito dias que estou aqui [no hospital] (Jaspe).

[...] procurava me dividir entre trabalho e ela. Não me divertia, não saía [...] me dedicava para ela, final de semana, feriado, era só para ela [...]. Estava com muita insônia, falta de apetite, comecei a emagrecer, falta de atenção [...] (Ametista).

Nestas descrições, os cuidadores se referem ao cuidado como algo desgastante, cansativo, porém, tentando enxergar as figuras que constituem o fundo das descrições, percebemos que o que é "saturador, cansativo, turbulento, difícil" nas vivências dos cuidadores não é o cuidado em si, mas o contexto que o entorna. Este contexto faz com que o cuidador perceba a circunstância do cuidado como uma barreira no seu processo de viver, o que constitui uma compreensão objetivista e unilateral, pois toda vivência ocorre de modo intersubjetivo e, como tal, sempre abre possibilidade à transcendência do eu, que, na perspectiva merleau-pontyana, constitui a sexualidade. ${ }^{9}$

Nesta compreensão de sexualidade, o sexual não é o genital, mas uma intencionalidade original que propicia a experiência do outro. ${ }^{9}$ Logo, ao visualizar a possibilidade da cessação de sua sexualidade, em função da iminência da morte da pessoa de quem cuida, muitas vezes, o familiar cuidador passa a apresentar atitudes de autodefesa, como por exemplo, quando Ametista diz: [...] eu tenho que sair, se eu ficar em casa eu não vou aguentar. Aí, eu saí, eu fui passar a virada do ano na praia, caracterizou um cuidado de si autêntico, uma atitude consciente de cuidado de si frente à vivência do cuidar do outro.

A percepção de estar lidando com uma doença degenerativa e que não tem cura faz com que os cuidadores visualizem a morte de seu familiar como uma alternativa de manutenção da própria 
existência. Este cuidado configura-se como autêntico. ${ }^{14}$ Vejamos a descrição que se segue:

[...] para certas pessoas que já viveram com câncer, seis meses foi rápido demais, mas para uma pessoa que está cuidando sozinha, seis meses é uma eternidade [...]. Eu comecei a orar, comecei a pedir a Deus: Oh, Senhor, Tu cura ou leva, faz o que é da tua vontade [...]. Deus me deu a resposta, porque quando foi naquele mesmo dia seis horas da tarde, minha mãe faleceu. [...] comecei a chorar e falar - obrigada, Senhor, obrigada, meu Deus, porque o Senhor me deu a resposta. [...] não queria perder minha mãe, porque é a única coisa que tenho (Ágata).

O desejo do cuidador, de antecipação da morte física da pessoa de quem ele cuida, constitui um desejo de interrupção da experiência do outro do outro. Como o cuidador poderia desejar a morte de um familiar o qual considera seu ente querido? Isto se mostra como uma ambiguidade que é própria da experiência perceptiva. Pode-se então compreender que o outro só me é importante quando me possibilita a experiência do outro do ponto de vista da gratificação pessoal.

Vale destacar que as noções de autenticidade e inautenticidade não têm um sentido moral, devendo ser vistos como modos de ser, modalidades de cuidar, ou seja, tem a ver com um saber e um não-saber de si, portanto, não se trata de fazer juízo de valor, de ser bom ou ruim ${ }^{14}$ : ambos compõem uma ambiguidade inerente ao cuidado. Sob o olhar merleau-pontyano, tal ambiguidade decorre da forma como percebemos o outro de quem o cuidador se ocupa. ${ }^{12}$ Diante do exposto, independentemente do sentido que se exprime em uma relação de cuidado, este sempre será autênti$\mathrm{co}$, na medida em que permite que o cuidador se torne um outro eu mesmo.

\section{CONSIDERAÇÕES FINAIS}

A partir das descrições vivenciais dos cuidadores, compreendemos que a experiência do cuidado exprime-se como um fenômeno, mostrando-se em si mesmo, a partir de si mesmo: ele nunca se mostra completamente, mas sempre em perspectiva. Logo, o cuidado desvela-se como uma experiência intersubjetiva, inerente à relação cuidador e pessoa cuidada, que se caracteriza por ser uma vivência ambígua, visto que a cada momento o cuidado se mostra em um perfil, arrastando consigo uma série de outros perfis, promovendo uma constante articulação entre uma natureza pré-reflexiva e outra refle- xiva, conforme descreve Merleau-Ponty em sua filosofia da experiência. ${ }^{7}$

O cuidado mostrou-se movido por uma intencionalidade. Esta nos faz perceber que o cuidado do outro sempre se constitui como um cuidado de si. Neste sentido, o estudo também possibilitou a percepção do cuidado sob uma nova perspectiva. O cuidado, que era compreendido como uma atitude de generosidade, ou seja, algo que é motivado por nossa subjetividade interior, que pertence ao cuidador e ele oferece ao outro por meio da relação sujeito-sujeito, passa a ser visto como algo que se desvela, que acontece na intersubjetividade.

A partir da compreensão da intercorporeidade do cuidar, percebemos que os cuidadores de pessoas com câncer também necessitam de cuidado. Este cuidado deve ir além de um investimento em aspectos determinantes e condicionantes de saúde, visualizando uma melhor qualidade de vida, mas na promoção de uma relação dialógica, criando possibilidades para que os cuidadores percebam o cuidado como oportunidade de transcendência.

Nesta perspectiva, o estudo mostrou-se relevante para a área de saúde, uma vez que abre possibilidades aos profissionais e gestores para a valorização e promoção de ações de cunho intersubjetivo, para o debate e a compreensão do contexto do cuidar de pessoas com câncer em estágio avançado e de seus cuidadores. Além disso, traz subsídios para sensibilizá-los para a necessidade de construção e adoção de políticas públicas efetivas, que incentivem o desenvolvimento de ações extra-hospitalares, como grupos de mútua ajuda, no sentido de permitir que o cuidado alcance maior número de pessoas, favoreça o compartilhamento de vivências e, enfim, proporcione um melhor enfrentamento das dificuldades no cuidar.

\section{REFERÊNCIAS}

1. Ministério da Saúde (BR), Instituto Nacional do Câncer. Estimativa 2010: incidência de câncer no Brasil / Instituto Nacional do Câncer [online]. Rio de Janeiro (RJ): INCA; 2010 [acesso 2011 Set 20]. Disponível em: http://www1.inca.gov.br/ estimativa/2010

2. Brasil. Constituição da República Federativa do Brasil. Brasília (DF): Senado Federal; 1988.

3. Organização Mundial da Saúde. Cuidados inovadores para condições crônicas: componentes estruturais de ação. Relatório mundial. Brasília (DF): OMS; 2003. 
4. Waldow VR. Cuidado humano: o resgate necessário $3^{\mathrm{a}}$ ed. Porto Alegre (RS): Sagra-Luzzatto; 2001.

5. Stein E. Seis estudos sobre "Ser e tempo" - Martin Heidegger. $2^{\mathrm{a}}$ ed. Petrópolis (RJ): Vozes; 1990.

6. Boff L. Saber cuidar: ética do homem - compaixão pela terra. Petrópolis (RJ): Vozes; 1999

7. Merleau-Ponty M. Fenomenologia da percepção. $2^{\mathrm{a}}$ ed. São Paulo (SP): Martins Fontes; 1999.

8. Merleau-Ponty M. O visível e o invisível. $4^{\mathrm{a}}$ ed. São Paulo: Perspectiva; 2000.

9. Merleau-Ponty M. A prosa do mundo. São Paulo (SP): Cosac \& Naify; 2002.

10. Sena ELS. A experiência do outro nas relações de cuidado: uma visão merleau-pontyana sobre as vivências de familiares cuidadores de pessoas com doença de Alzheimer [tese]. Florianópolis (SC): Universidade Federal de Santa Catarina. Programa de Pós-Graduação em Enfermagem; 2006.

11. Ministério da Saúde (BR), Conselho Nacional de Saúde, Comissão Nacional de Ética em Pesquisa. Resolução No 196 de 10 de outubro de 1996: diretrizes e normas regulamentadoras de pesquisa envolvendo humanos. Brasília (DF): MS; 1996.

12. Sena ELS, Gonçalves LHT. Vivências de familiares cuidadores de pessoas idosas com doença de Alzheimer: perspectiva da filosofia de Merleau-
Ponty. Texto Contexto Enferm. 2008 Abr-Jun; 17(2):232-40.

13. Sena ELS, Gonçalves LHT. Intercorporeidade na experiência do cuidado: familiar cuidador e portador da doença de Alzheimer. In: Silva AL; Gonçalves LHT. Cuidado à pessoa idosa: estudos no contexto luso-brasileiro. Porto Alegre (RS): editora sulina; 2010. p.193-218.

14. Heidegger M. Ser e tempo. Parte I. Petrópolis (RJ): Vozes; 1993.

15. Husserl E. Meditações cartesianas: introdução à fenomenologia. Portugal: RÉS; 1983.

16. Stuart GW, Laraia MT. Enfermagem psiquiátrica: princípios e práticas. $6^{\mathrm{a}}$ ed. Porto Alegre (RS): Artmed; 2001.

17. Sá AC. Reflexão sobre o cuidar em enfermagem: uma visão do ponto de vista da espiritualidade humana e da atitude crística. O Mundo da Saúde. 2009 AbrJun; 33(2):205-17

18. Carvalho MMMJ. Introdução à Psiconcologia. Campinas (SP): Editora Livro Pleno; 2003.

19. Pimentel AV, Panobianco MS, Almeida AM, Oliveira ISB. A percepção da vulnerabilidade entre mulheres com diagnóstico avançado do câncer do colo do útero. Texto Contexto Enferm. 2011 Abr-Jun; 20(2):255-62. 